\title{
New paleoclimatic evidence of an extraordinary rise in temperature in the Northern Hemisphere in the last 3-4 decades.
}

Maxim Ogurtsov ( $\square$ maxim.ogurtsov@mail.ioffe.ru )

loffe Institute: FBGUN Fiziko-tehniceskij institut imeni A F loffe Rossijskoj akademii nauk https://orcid.org/0000-0002-4517-9257

\section{Research Article}

Keywords: Global warming, Paleoclimatology, Dendroclimatology, Climate variability

Posted Date: February 11th, 2022

DOI: https://doi.org/10.21203/rs.3.rs-1299727/v1

License: (c) (i) This work is licensed under a Creative Commons Attribution 4.0 International License.

Read Full License 


\section{Abstract}

Prognosis of temperature changes in the Northern Hemisphere for the period 1980-2020 was made using four temperature paleoreconstructions covering the last 1-2 millennia and ending 1979-1993. A part of paleodata before 1860 (prior to the beginning of a noticeable anthropogenic impact) was used as an information bank. Forecasts were made using nonlinear prediction method which is based on the reconstruction of the trajectory of the predicted series dynamic system in a pseudo-phase space. In all four cases, the forecast gave either a decrease or a very slight increase in temperature during 1980-2020. Statistical experiments performed with using prediction errors have shown that a rise in temperature by $0.15-0.20^{\circ} \mathrm{C}$ degrees in the indicated epoch is not excluded, but its probability is low $(P<0.15)$. This means that if the climate in the 20th - early 21 st century was controlled by the same dynamic system as before 1860, the noticeable warming of the Northern Hemisphere in 1980-2020 should not be observed. While the actual rise of the recorded temperature is sharp and reaches $1.0^{\circ} \mathrm{C}$. Such divergence indicates that the climate of the Northern Hemisphere in the last 30-40 years was significantly affected by an additional factor that did not act in the previous 1-2 millennia. The possible influence of the problem of divergence in tree-ring research on the result obtained is discussed.

\section{Introduction}

Global warming (GW) - rise of the global temperature during the last 150 years - has become the most important problem of climatology since the end of the 20th century. Recently, the Intergovernmental Panel on Climate Change (IPCC) issued its 6th Assessment Report (IPCC, 2021) which stated "The likely range of human-induced warming in global-mean surface temperature (GSAT) in 2010-2019 relative to 18501900 is $0.8^{\circ} \mathrm{C}-1.3^{\circ} \mathrm{C}$, encompassing the observed warming of $0.9^{\circ} \mathrm{C}-1.2^{\circ} \mathrm{C}$, while the change attributable to natural forcings is only $-0.1^{\circ} \mathrm{C}-0.1^{\circ} \mathrm{C}$." Therefore, according to IPCC (2021), almost all of the temperature rise observed over the past 150 years can be attributed to human activities while contribution of natural factors is minimal. However, some other studies have come to different conclusions. E.g. Connolly et al. (2021) showed that only changes of total solar irradiance (TSI) could explain at least half of global warming since the 19th century. Lüdeke et al. (2013) showed that variations of the temperature in Central Europe after 1756 AD may be the result of the intrinsic dynamics of climatic system. Problem of assessing the contribution of various processes to global climate change is that our information about these processes - the parameters of climate models - is often approximate and insufficiently reliable. Our knowledge on some potential climatic forsings (solar irradiance, albedo change due to land use, space weather, $\mathrm{NO}_{x}$ etc.) as well as on structure of feedbacks is incomplete. This concerns, for example, the possible influence of solar-cosmic factors on the climate. That is why the parameters of many modern climate models have huge uncertainties. This makes it possible to fit the calculated temperature to the measured one in rather different ways. E.g. model calculations performed by Ogurtsov (2007) and Ogurtsov and Veretenenko (2017) showed that arbitrary manipulation of the input parameters of the model, none of which is known accurately and reliably enough, can explain large part of the GW with completely ignoring the greenhouse effect. 
Ogurtsov and Lindholm (2006) and Ogurtsov et al. (2013) suggested another way to estimate the possible contribution of natural climatic fluctuations to the $\mathrm{GW}$. They used paleoclimatic information to solve this problem. In this paper the approach developed by Ogurtsov et al. (2013) was applied to the most recent temperature data. I estimated the probability that the warming in the Northern Hemisphere over the past 30-40 years is a result of climatic changes caused by natural factors (intrinsic dynamics of the Earth's climate, changes in solar and volcanic activity, etc.) and is not associated with anthropogenic impact using the following algorithm: I assumed that if the anthropogenic impact is weak and the climate of the last 150 years has been controlled by the same dynamic system as during the last millennia, the current state of the climate is a natural result of its past. This, in turn, means that paleoclimatic data about the past climate can be used to predict its future. In this case, using the Northern Hemisphere temperature reconstructions covering the past 1-2 millennia and ending in 1980-1993, we can predict further temperature changes in 1990-2020. This forecast will evidently describe the most probable scenario of natural climate changes in the specified period. By comparing the forecast results with real instrumental data, one can estimate the possible contribution of natural climatic variations to the warming of the last 30-40 years. The obvious advantage of this approach is that it does not require any theoretical assumptions about the forcings that affect the Earth's climate. Indeed, although our knowledge of the various factors affecting the climate is limited, temperature changes over the past 1-2 millennia should contain all the necessary information.

\section{Results And Discussion}

From the available paleoclimatic reconstructions, I have selected the four ones, which describe the warming of the 20th century as not anomalous and, hence, the most matching to hypothesis of the mostly natural warming of the last 150 years: the time series of Briffa (2000), Esper et al. (2002), Moberg et al. (2005), Loehle (2007). These data sets are described in Table 1.

Table 1

Millennial-length reconstructions of the Northern Hemisphere temperature used in analysis.

\begin{tabular}{|c|c|c|c|}
\hline Source & $\begin{array}{l}\text { Time } \\
\text { span }\end{array}$ & Geographic region & Proxies used \\
\hline $\begin{array}{l}\text { Loehle } \\
(2007)\end{array}$ & $\begin{array}{l}16- \\
1980\end{array}$ & Northern Hemisphere & $\begin{array}{l}\Delta^{18} \mathrm{O}, \text { pollen, di-atoms, } \mathrm{Mg} / \mathrm{Ca} \text {, sta- } \\
\text { lagmite, historical data }\end{array}$ \\
\hline $\begin{array}{l}\text { Esper et al } \\
(2002)\end{array}$ & $\begin{array}{l}850- \\
1992\end{array}$ & $\begin{array}{l}\text { Extratropical part of the } \\
\text { Hemisphere }\left(\phi>30^{\circ} \mathrm{N}\right)\end{array}$ & Tree-ring \\
\hline $\begin{array}{l}\text { Moberg et } \\
\text { al. (2005) }\end{array}$ & $\begin{array}{l}1- \\
1979\end{array}$ & Northern Hemisphere & $\begin{array}{l}\text { Tree-ring, } \Delta^{18} \mathrm{O} \text {, pollen, } \mathrm{Mg} / \mathrm{Ca} \text {, diatoms, } \\
\text { stalag-mite, borehole }\end{array}$ \\
\hline $\begin{array}{l}\text { Briffa } \\
(2000)\end{array}$ & $\begin{array}{l}1- \\
1993\end{array}$ & $\begin{array}{l}\text { Northern part of the } \\
\text { Hemisphere } \\
\left(\phi>60^{\circ} \mathrm{N}\right)\end{array}$ & Tree-ring \\
\hline
\end{tabular}


All the four paleorecords, averaged by 13 years and interpolated by decades, are shown in Fig. 1:

The nonlinear predictions were made using the method of analogs, which is based on the reconstruction of the trajectory of the dynamic system of the predicted series in a pseudo-phase space and is a modification of the method used by Sugihara and May (1990). Data covering time intervals up to 1860 (87-185 points prior to start of a strong anthropogenic impact) were used to construct a library of past patterns i.e. as a bank of information. Step of prediction was 10 years. Uncertainties of the forecast were estimated by means of prediction of 10-12 points of each series during 1860-1960. The forecast results are shown in Figure 2.

Figure 2 shows that if the GW is the result of natural climatic variability, i.e. the climate of the past 150 years is governed by the same dynamic system as in the previous one to two millennia, the increase in the average temperature of the Northern Hemisphere during 1990-2020 appears unlikely even given the large forecast uncertainties. Predictions made by Ogurtsov and Lindholm (2006) and Ogurtsov et al. (2013) led to similar conclusions. Lüdeke et al. (2013), who considered temperature changes in Central Europe since 1757 as a result of mainly internal oscillations of the climate system, concluded that temperatures should drop after 2000 (see their Fig. 6). Scafetta (2012), who used an empirical climate model based on astronomical cycles, also predicted only very moderate temperature increases during 2010-2020. While the observed instrumental temperature increased sharply throughout the entire four decades: see Fig. 3.

Figure 3 shows that observed instrumental temperature of the Northern Hemisphere increases by $1.04^{\circ} \mathrm{C}$ during $1980-2020 \mathrm{AD}$ with a slope of the linear trend $\mathrm{a}_{\mathrm{obs}}=0.26^{\circ} \mathrm{C} / 10$ years $\left(0.87^{\circ} \mathrm{C}\right.$ and $\mathrm{a}_{\mathrm{obs}}=0.29^{\circ} \mathrm{C} / 10$ years during 1990-2020). In the extratropical part of the Northern Hemisphere, whose temperature was reconstructed by Briffa (2000) and Esper et al. (2002), the increase of temperature was larger. Increase in rural Northern Hemisphere temperature series is also close to $1.0^{\circ} \mathrm{C}$ (see Fig. $7 \mathrm{~h}$ after Connolly et al. (2021)). Scafetta (2020) arrived at conclusion that up to $25 \%$ of the observed temperature rise could be associated with non-climatic biases. In this case the slope during $1980-2020$ would be $a_{o b s}=0.196^{\circ} \mathrm{C} /$ 10 years $\left(0.217^{\circ} \mathrm{C} / 10\right.$ years during $\left.1990-2020\right)$. Whereas the corresponding slopes of the predicted temperature for the same time interval are $(-0.011--0.085)^{\circ} \mathrm{C} / 10$ years. The probabilities that the slope of the predicted temperature actually reaches some values $a_{i}$ were evaluated by means of a statistical experiment. It were performed a few thousands of simulations in each of which the surrogate series was constructed by adding a random sequence to the record of temperature predicted for 1980-2020. Each random set was generated by Gaussian noise with standard deviation equal to the corresponding value of the prognosis uncertainty. By this way, the probability $P$ of such surrogate series to have linear trend with the determined angle was estimated - see Table 1. 
Table 2

The probability that the slope of the predicted temperature trend in the Northern Hemisphere during 19802020 will reach the slope of the real trend $a_{o b s}$ or values $a_{o b s} \times n$.

\begin{tabular}{|c|c|c|c|c|c|c|c|}
\hline & \multirow[t]{2}{*}{$\begin{array}{l}\text { Time } \\
\text { span }\end{array}$} & \multirow[t]{2}{*}{$\begin{array}{l}\text { Angle of the predic-ted trend } \\
\left({ }^{\circ} \mathrm{C} / 10 \text { years) }\right.\end{array}$} & \multicolumn{5}{|c|}{$\begin{array}{l}\text { The probability that the angle of } \\
\text { inclination will reach the value: }\end{array}$} \\
\hline & & & $a_{\text {obs }}$ & $\begin{array}{l}a_{\text {obs }} \\
\times \\
0.75\end{array}$ & $\begin{array}{l}a_{\text {obs }} \\
\times \\
0.50\end{array}$ & $\begin{array}{l}a_{\text {obs }} \\
x \\
0.20\end{array}$ & $\begin{array}{l}a_{\text {obs }} \\
\times 0.15\end{array}$ \\
\hline $\begin{array}{l}\text { Loehle } \\
\text { (2007) }\end{array}$ & $\begin{array}{l}1980- \\
2020\end{array}$ & -0.0175 & $<10^{-3}$ & $<10^{-3}$ & $<10^{-3}$ & 0.002 & 0.015 \\
\hline $\begin{array}{l}\text { Esper et al } \\
(2002)\end{array}$ & $\begin{array}{l}1990- \\
2020\end{array}$ & -0.085 & $<10^{-3}$ & $<10^{-3}$ & 0.001 & 0.024 & 0.038 \\
\hline $\begin{array}{l}\text { Moberg et } \\
\text { al. (2005) }\end{array}$ & $\begin{array}{l}1980- \\
2020\end{array}$ & -0.0106 & $<10^{-3}$ & $<10^{-3}$ & 0.003 & 0.113 & 0.161 \\
\hline Briffa (2000) & $\begin{array}{l}1990- \\
2020\end{array}$ & -0.074 & $<10^{-3}$ & $<10^{-3}$ & $<10^{-3}$ & 0.005 & 0.013 \\
\hline
\end{tabular}

The statistical experiments carried out indicate that from the point of view of modern paleoclimatology, a natural rise in temperature in the Northern Hemisphere during last three-four decades by $0.15-0.20^{\circ} \mathrm{C}$, caused by internal fluctuations of the climate system, is not completely excluded but is not likely $(P \leq 0.10-0.15)$. And the actually observed rise of $0.9-1.0^{\circ} \mathrm{C}$ is impossible.

However, in order to assess reliability of the obtained results correctly one should take into account the divergence problem - a well-known anomalous reduction in the sensitivity of tree growth to changing temperature (ARS). ARS has been detected in many dendrochronological records over the last decades of the 20th century (Briffa et al., 1998B, Briffa, 2000, D’Arrigo et al., 2007, Wilson et al., 2007, Esper and Frank, 2009). An evident underestimation of recent warming in tree-ring based reconstructions is illustrated in Fig.4 (see also Fig.12 after Scafetta, 2021 and Fig.6 after Briffa et al., 1998A ).

Figure 4 Thick black line represents instrumentally measured temperature Northern Hemisphere (https://data.giss.nasa.gov/gistemp/tabledata_v4/NH.Ts+dSST.txt), dotted black line- reconstruction of Jones et al. (1998), thick grey- reconstruction of Briffa (2000), thin black line - reconstruction of Esper et al (2002). All the data sets smoothed over 15 years.

Despite some possible explanations listed by D'Arrigo et al. (2007) and Loehle (2009), the divergence problem has not yet been resolved. Obviously, if modern temperature reconstructions poorly reflect the sharp rise in temperature in recent decades, it is possible that similar increases in previous epochs were not recorded by them either. Then the tree-ring reconstructions contain only limited and approximate information about the temperature changes in the past. In this case, the forecast results based on limited information should be regarded as rather qualitative. 
On the other hand, the Loehle (2007) reconstruction was made without using any tree-ring data, so the results of the forecast made with it are still valid in any case. Thus, the uncertainty associated with the divergence problem may somewhat reduce the reliability of the forecasts obtained, but unlikely can reverse them.

\section{Summary}

The results of my study showed, that the hypothesis about the predominantly natural character of the warming of the Northern Hemisphere in the past 30-40 years meets with serious difficulties. From the point of view of data accumulated by paleoclimatology, the observed increase appears to be very unusual or even anomalous. Natural drivers could warm the Northern Hemisphere by $0.1-0.2^{\circ} \mathrm{C}$ but this is unclear. A number of predictions of the temperature change after AD 2000, made using the assumption of a purely natural origin of the variations in the Earth's climate in recent centuries, have also turned out to be not very successful. Given all this, it is reasonable to conclude that, at least for the last four decades, the climate system actually was perturbed by an additional factor that did not act in the past. However, we should not forget that we do not know how accurately the available paleorecords reconstruct the real past temperature of the Northern Hemisphere.

\section{Declarations}

\section{Statements and Declarations}

Data used in this work are available from the public domain https://www.ncei.noaa.gov.

\section{References}

1. Vaganov EA (1998A).) Trees tell of past climates: but are they speaking less clearly today? Phil Trans R Soc Lond B 353(1365):65-73. doi:10.1098/rstb.1998.0191. Grudd H (

2. Briffa KR, Schweingruber FH, Jones PD, Osborn TJ (1998B) Reduced sensitivity of recent tree growth to temperature at high northern latitudes. Nature 391:678-682. DOI:10.1038/35596

3. Briffa KR (2000) Annual climate variability in the Holocene: interpreting the message of ancient trees. Quat Sci Rev 19:87-105. DOI:10.1016/S0277-3791(99)00056-6

4. Connolly R, Soon W, Connolly M, Baliunas S, Berglund J, Butler CJ, Cionco RG, Elias AG, Fedorov VM, Harde H (2021) How much has the Sun influenced Northern Hemisphere temperature trends? An ongoing debate. Res Astron Astrophys 21:131. doi:10.1088/1674-4527/21/6/131

5. D'Arrigo R, Wilson R, Liepert B, Cherubini $P$ (2007) On the 'divergence problem' in northern forests: A review of the tree-ring evidence and possible causes. Glob Planet Change 60(3-4):289-305. doi:10.1016/j.gloplacha.2007.03.004

6. Esper J, Cook ER, Schweingruber FH (2002) Low-Frequency signals inl tree-ring chronologies for reconstructing past temperature variability. Science 295(5563):2250-2253. doi: 


\subsection{6/science.1066208}

7. Esper J, Frank D (2009) Divergence pitfalls in tree-ring research. Clim Change 94:261-266. DOI:10.1007/s10584-009-9594-2

8. Jones PD, Briffa KR, Barnett TP, Tett SFB (1998) High-Resolution palaeoclimatic records for the last millennium: Interpretation, integration and comparison with General Circulation Model control-run temperatures. The Holocene 84:455-471. https://doi.org/10.1191/095968398667194956

9. Loehle CA (2007) 2000-year global temperature reconstruction based on non-treering proxies. Energy Environ 18(7-8):1049-1058. DOI:10.1260/095830507782616797

10. Loehle CA (2009) Mathematical analysis of the divergence problem in dendroclimatology. Clim Change 94:233-245. https://doi.org/10.1007/s10584-008-9488-8

11. Lüdecke H-J, Hempelmann A, Weiss CO (2013) Multi-periodic climate dynamics: spectral analysis of long-term instrumental and proxy temperature records. Clim Past 9:447-452. doi:10.5194/cp-9-4472013

12. Moberg A, Sonechkin DM, Holmgren K, Datsenko MM, Karlen W (2005) High variable Northern Hemisphere temperatures reconstructed from low- and high-resolution proxy data. Nature 433(7026):613-617. doi: 10.1038/nature03265

13. Ogurtsov MG, Lindholm M (2006) Uncertainties in assessing Global Warming during the 20th century: disagreement between key data sources. Energy Environ 17(5):685-706. DOI:10.1260/0958305X.17.5.685

14. Ogurtsov MG (2007) On the possible contribution of solar-cosmic factors to the global warming of XX century. Bull Russ Acad Sci Phys 71:1018-1020. https://doi.org/10.3103/S1062873807070374

15. Ogurtsov M, Lindholm M, Jalkanen R (2013) Global warming- scientific facts, problems and possible scenarios. In: Tarhule A (ed.) Climate variability- regional and thematic patterns. Rieka, InTech, p. 75103, ISBN 978-953-51-1187-0. DOI: 10.5772/56077. Available from:

https://www.intechopen.com/chapters/45212

16. Ogurtsov MG, Veretenenko SV (2017) Possible contribution of variations in the galactic cosmic ray flux to the global temperature rise in recent decades. Geomagn Aeron 57(8):886-891.

$10.1134 /$ S0016793217070143

17. Scafetta N (2021) Detection of non-climatic biases in land surface temperature records by comparing climatic data and their model simulations. Clim Dyn 56:2959-2982. https://doi.org/10.1007/s00382-021-05626-x

18. Sugihara G, May RM (1990) Nonlinear forecasting as a way of distinguishing chaos from measurement error in time series. Nature 344:734-741. https://doi.org/10.1038/344734a0

19. Wilson R, D'Arrigo R, Buckley B, Büntgen U, Esper J, Frank D, Luckman B, Payette S, Vose R, Youngblut $D$ (2007) A matter of divergence-tracking recent warming at hemispheric scales using tree-ring data. J Geophys Res 112:D17103:1-17. doi:10.1029/2006JD008318

\section{Figures}




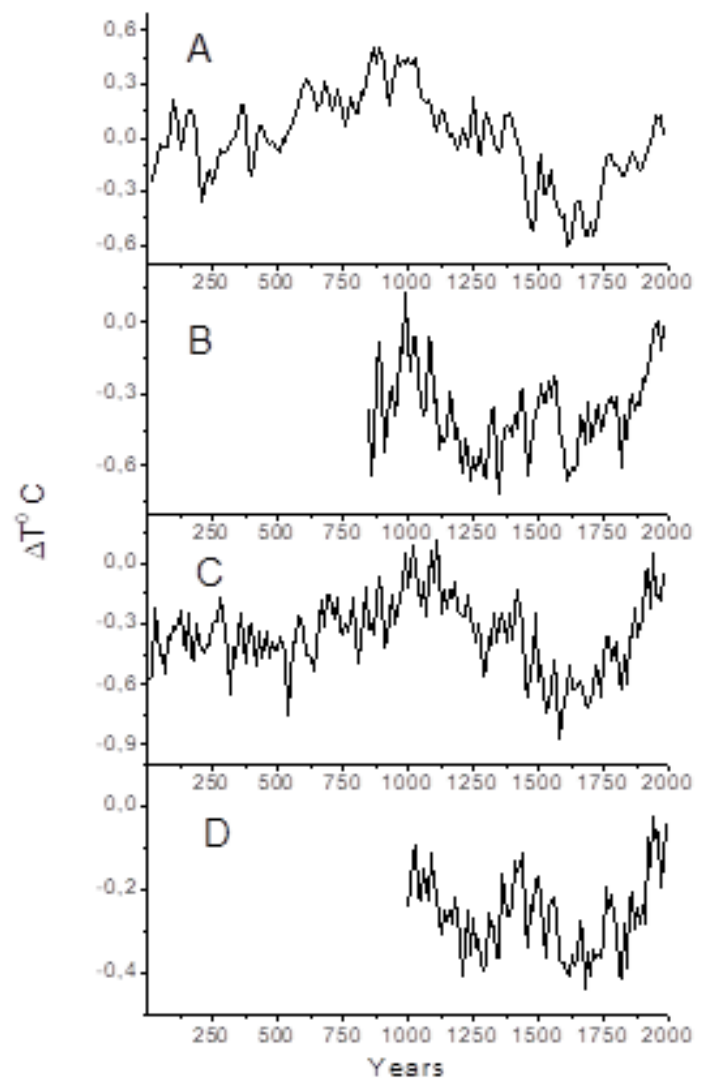

Figure 1

Reconstructions of the Northern Hemisphere temperature over the last 1-2 millennia: A - the non treering proxy of Loehle (2007); B - the tree-ring proxy of Esper et al. (2002); C - the multiproxy of Moberg et al. (2005); D - the tree-ring proxy of Briffa (2000). All the data sets were smoothed by 13 years and interpolated by decades. 


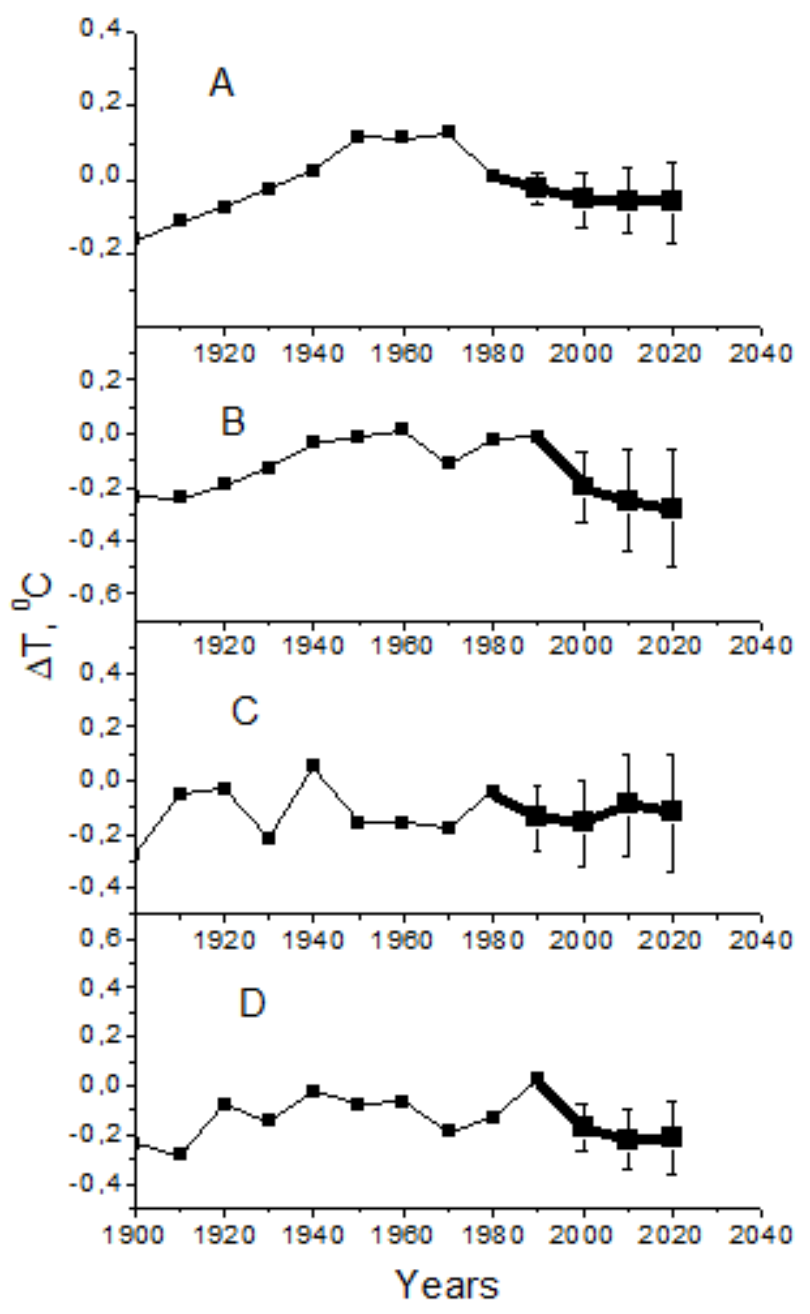

\section{Figure 2}

Forecasts of future Northern Hemisphere temperatures based on: A - reconstruction by Loehle (2007); B - reconstruction by Esper et al. (2002); C - reconstruction by Moberg et al. (2005); D - reconstruction by Briffa (2000). Predicted values are shown with thick lines with large quadrats. This prediction was made using the embedding dimension $\mathrm{d}=3$ and eight nearest neighbors 


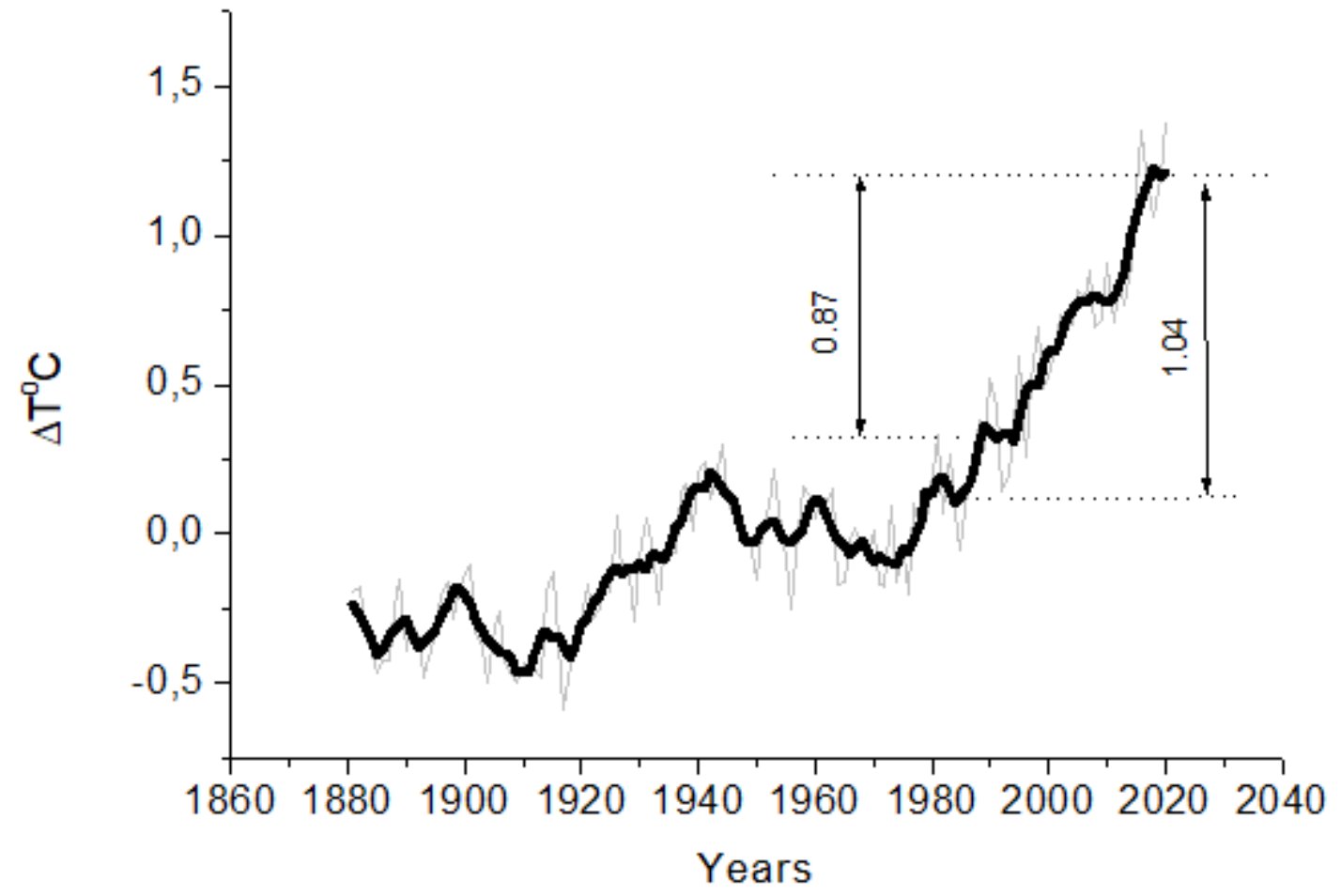

Figure 3

Observed changes in an average annual temperature of the Northern Hemisphere. Thin line represents raw data. Thick line represents 5 year average.

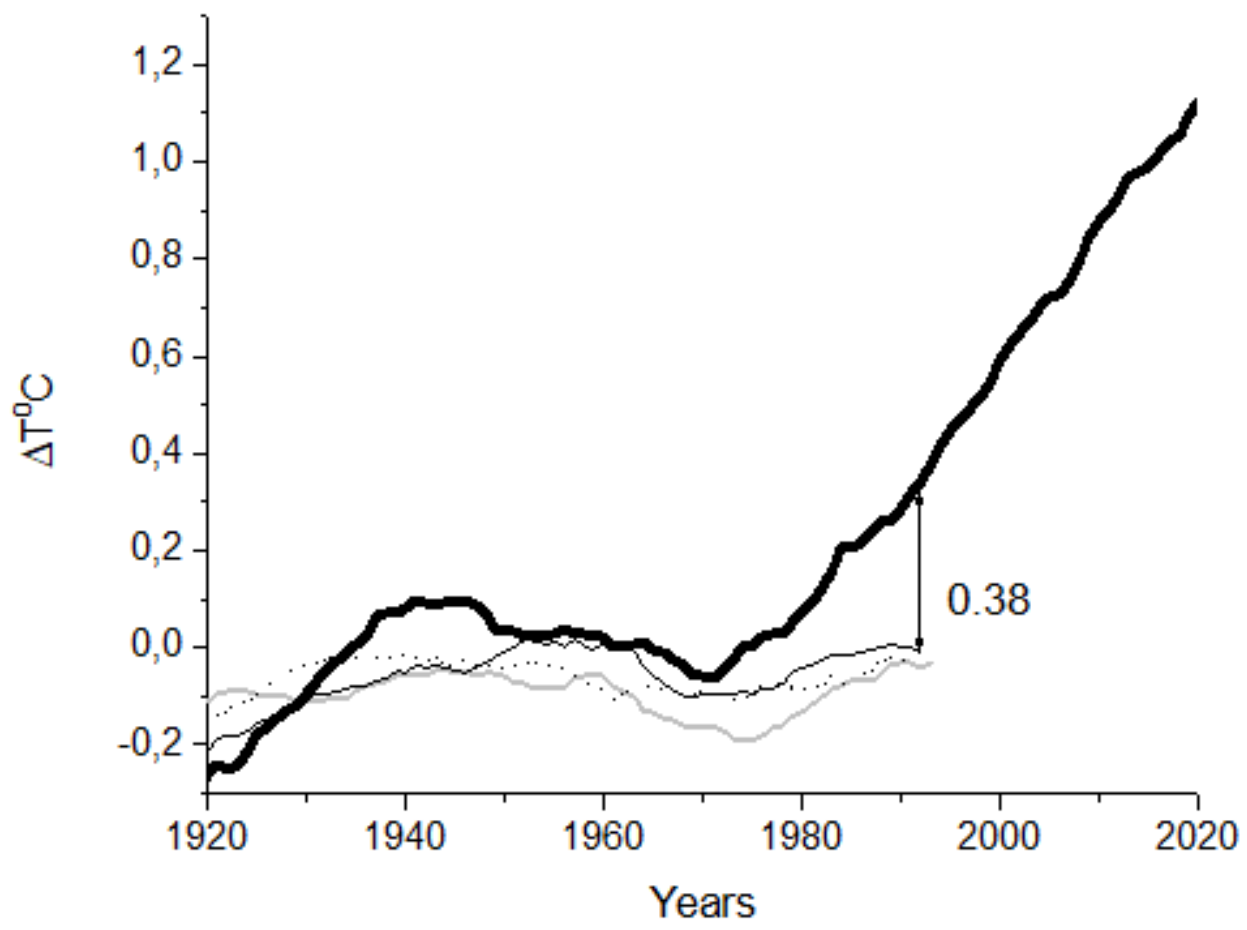

Figure 4 
Thick black line represents instrumentally measured temperature Northern Hemisphere (https://data.giss.nasa.gov/gistemp/tabledata_v4/NH.Ts+dSST.txt), dotted black line- reconstruction of Jones et al. (1998), thick grey - reconstruction of Briffa (2000), thin black line - reconstruction of Esper et al (2002). All the data sets smoothed over 15 years. 